\title{
A Multicenter VA Study of the Format and Content of Internal Medicine Morning Report
}

\author{
Daniel B. Heppe, $M D^{1,2}$ (D) Albertine S. Beard, $M D^{3,4}$, Paul B. Cornia, $M D^{5,6}$, \\ Tyler J. Albert, MD ${ }^{5,6}$, Azadeh Lankarani-Fard, MD ${ }^{7,8}$, Joel M. Bradley, MD ${ }^{9,10,}$ \\ Michelle M. Guidry, MD ${ }^{17,12}$, Brian Kwan, MD ${ }^{13,14}$, Anand Jagannath, MD ${ }^{13,14}$, \\ Matthew Tuck, MD ${ }^{15,16}$, Kathlyn E. Fletcher, MD ${ }^{17,18}$, Elizabeth S. Gromisch, Ph.D. 19,20,21, \\ and Craig G. Gunderson, $M D^{22,23}$
}

'Department of Medicine, University of Colorado School of Medicine, Aurora, CO, USA; ${ }^{2}$ VA Eastern Colorado Health Care System, Aurora, CO, USA; ${ }^{3}$ Department of Medicine, University of Minnesota School of Medicine, Minneapolis, MN, USA; ${ }^{4}$ Minneapolis VA Health Care System, Minneapolis, MN, USA; 5 University of Washington School of Medicine, Seattle, WA, USA; ${ }^{6}$ VA Puget Sound Health Care System, Seattle, WA, USA; ${ }^{7}$ David Geffen School of Medicine, Los Angeles, CA, USA; ${ }^{8}$ VA Greater Los Angeles Healthcare System, Los Angeles, CA, USA; ${ }^{9}$ Geisel School of Medicine, Hanover, NH, USA; " White River Junction VA Medical Center, Hartford, VT, USA; "Tulane University School of Medicine, New Orleans, LA, USA; ${ }^{12}$ Southeast Louisiana Veterans Health Care System, New Orleans, LA, USA; ${ }^{13}$ University of California San Diego School of Medicine, San Diego, CA, USA; ${ }^{14}$ VA San Diego Healthcare System, San Diego, CA, USA; ${ }^{15}$ George Washington University School of Medicine, Washington, DC, USA; ${ }^{16}$ Washington DC VA Medical Center, Washington, DC, USA; ${ }^{17}$ Medical College of Wisconsin, Wauwatosa, WI, USA; ${ }^{18}$ Milwaukee VA Medical Center, Milwaukee, WI, USA; ${ }^{19}$ Mandell Center for Multiple Sclerosis, Mount Sinai Rehabilitation Hospital, Trinity Health of New England, Hartford, CT, USA; ${ }^{20}$ Department of Neurology, University of Connecticut School of Medicine, Farmington, CT, USA; ${ }^{21}$ Departments of Rehabilitative Medicine and Medical Sciences, Frank H. Netter MD School of Medicine at Quinnipiac University, Hamden, CT, USA; ${ }^{22}$ Yale University School of Medicine, New Haven, CT, USA; ${ }^{23}$ VA Connecticut Healthcare System, West Haven, CT, USA.

BACKGROUND: There are more than five hundred internal medicine residency programs in the USA, involving 27,000 residents. Morning report is a central educational activity in resident education, but no recent studies describe its format or content.

OBJECTIVE: To describe the format and content of internal medicine morning reports.

DESIGN AND PARTICIPANTS: Prospective observational study of morning reports occurring between September 1, 2018, and April 30, 2019, in ten different VA academic medical centers in the USA.

MAIN MEASURES: Report format, number and type of learner, number and background of attending, frequency of learner participation, and the type of media used. Content areas including quality and safety, high-value care, social determinants of health, evidence-based medicine, ethics, and bedside teaching. For case-based reports, the duration of different aspects of the case was recorded, the ultimate diagnosis when known, and if the case was scripted or unscripted.

RESULTS: A total of 225 morning reports were observed. Reports were predominantly case-based, moderated by a chief resident, utilized digital presentation slides, and involved a range of learners including medicine residents, medical students, and non-physician learners. The most common attending physician present was a hospitalist. Reports typically involved a single case, which the chief resident reviewed prior to report and prepared a teaching

Electronic supplementary material The online version of this article (https://doi.org/10.1007/s11606-020-06069-6) contains supplementary material, which is available to authorized users.

Received March 8, 2020

Accepted July 15, 2020

Published online August 10, 2020 presentation using digital presentation slides. One-half of cases were categorized as either rare or life-threatening. The most common category of diagnosis was medication side effects. Quality and safety, high-value care, social determinants of health, and evidence-based medicine were commonly discussed. Medical ethics was rarely addressed.

CONCLUSIONS: Although a wide range of formats and content were described, internal medicine morning report most commonly involves a single case that is prepared ahead of time by the chief resident, uses digital presentation slides, and emphasizes history, differential diagnosis, didactics, and rare or life-threatening diseases.

KEY WORDS: morning report; internal medicine residency; education.

J Gen Intern Med 35(12):3591-6

DOI: $10.1007 / \mathrm{s} 11606-020-06069-6$

(c) Society of General Internal Medicine 2020

ccording to a recent survey by the American Medical
more than 500 internal medicine residency programs with
more than 27,000 trainees in the USA. ${ }^{1}$ A recent time motion
study found that the average internal medicine intern spends
more than one hour per day at educational conferences. ${ }^{2}$ One
of most enduring of these conferences is morning report, an
often case-based educational conference traditionally held in
the morning. Surveys of residents have consistently found that
morning report is viewed as the most important educational
conference. ${ }^{3,4}$ Studies from the 1980 s demonstrated that 
morning report was held in nearly all internal medicine residency programs and typically consisted of post-call residents presenting admissions to the chief of medicine and other prominent faculty members who reviewed the cases for quality, patient safety, and resident evaluation. ${ }^{4,5}$ Typically, the chair of the department led morning report and commonly overnight admissions were reviewed unscripted. ${ }^{5-8}$ There are however multiple other potential formats for morning report, including concentrating on one or two cases, prepared cases, and lecture-based formats. Reports may also be adapted to emphasize certain aspects of medical education such as clinical reasoning or evidence-based medicine. In the 1980s and 1990s, several single-center studies described certain aspects of morning report ${ }^{9-12}$ but no recent study has described the range of formats, participants, use of media, types of cases, and the relative amount of time devoted to different aspects of case presentation including history, physical exam, diagnosis, and management. In the current study, we describe the current structure and format of morning reports in different residency programs across the USA as well as the diagnoses that are discussed.

\section{METHODS}

\section{Study Setting}

We observed internal medicine morning report at ten different Veterans Health Administration Academic Medical Centers across the USA. Sites were recruited from the Veteran's Affairs National Academic Hospitalist Work Group. The ten sites were the Veterans Affairs hospitals in Seattle, Los Angeles, San Diego, Denver, Minneapolis, Milwaukee, New Orleans, Washington D.C., West Haven, Connecticut, and White River Junction, Vermont. Each hospital has an Accreditation Council for Graduate Medical Education (ACGME) accredited internal medicine residency program with a university affiliation with between 57 and 186 internal medicine residents. Individual hospitals ranged in size from 41 to 459 beds.

\section{Study Design}

We conducted a prospective observational study of the format, structure, and content of internal medicine morning report. At each participating site, a physician-investigator observed a series of morning reports and collected data on a range of variables including the overall format, number and type of learners, the number and background of attendings, the frequency of learner participation, the type of media used including the number and content of digital presentation slides, and the method of learner engagement such as open-ended questions or small group discussions. We recorded whether certain content areas were discussed, including quality and safety, high-value care, social determinants of health, evidencebased medicine, ethics, and bedside teaching. For case-based reports, we recorded the duration of time spent discussing different aspects of the case, the ultimate diagnosis when known, and if the case was prepared by the moderator in advance. Lastly, we recorded any distractions such as pages and cell phone use by learners and attendings. The Veterans Affairs Central Institutional Review Board determined that the study was exempt from local Institutional Review Board review because it involved a normal educational practice in a common setting. Local IRB exemption procedures were followed at each site.

\section{Data Collection}

Site investigators prospectively observed morning report between September 1, 2018, and April 30, 2019. A standardized data collection sheet was used. Prior to formal data collection, site investigators each observed two practice reports and the results were reviewed during monthly conference calls. Site investigators were instructed to count themselves as an attending only if they normally would have been present for report independent of the study. For recording cell phone use, if learners were asked to use their cell phones for report, this was not included.

\section{Data Analysis}

Most variables were described using simple descriptive statistics such as frequencies and medians. For variables related to the diagnosis discussed, analysis was restricted to the reports that were case-based and ultimately presented a known diagnosis. Differences between categories of nominal variables were assessed using single-variable chi-square. $p$ values $<$ 0.05 were considered significant. All analysis was performed using SPSS version 24.0 (Chicago, IL). Diagnoses were rated as rare/common and severe/not severe by two independent reviewers. The level of agreement between reviewers was described using Cohen's kappa statistic. For interpretation, kappa values of $0.41-0.60$ were considered moderate, $0.61-$ 0.80 substantial, and $0.81-0.99$ almost perfect. ${ }^{13}$

\section{RESULTS}

\section{Site Characteristics}

The general characteristics of the participating sites are reported in Table 1. Morning report started at varied times, ranging from 7:30 a.m. to 3 p.m. Four of the sites held report in the afternoon. The duration of report was one hour at seven of the sites and $45 \mathrm{~min}$ at the other three. Sites varied in whether food was supplied, whether all teams were expected to attend, and number of reports per week. No site had weekend reports.

\section{Structure and Content of Reports}

A total of 225 individual morning report conferences were observed. The overall structure and content of these conferences is reported in Table 2. One hundred ninety-three (86\%) 
Table 1 Overview of Participating Sites

\begin{tabular}{|c|c|c|c|c|c|c|c|c|}
\hline Location & Start & $\begin{array}{l}\text { Duration } \\
\text { (min) }\end{array}$ & $\begin{array}{l}\text { Food } \\
\text { provided }\end{array}$ & $\begin{array}{l}\text { Interns } \\
\text { pagers held }\end{array}$ & $\begin{array}{l}\text { All teams } \\
\text { expected }\end{array}$ & $\begin{array}{l}\text { Reports per } \\
\text { week }\end{array}$ & $\begin{array}{l}\text { Weekend } \\
\text { reports }\end{array}$ & $\begin{array}{l}\text { No. reports } \\
\text { observed }\end{array}$ \\
\hline Minneapolis & $08: 15$ & 45 & $\mathrm{~N}$ & $\mathrm{~N}$ & $\mathrm{~N}$ & 5 & $\mathrm{~N}$ & 38 \\
\hline New Haven & $\begin{array}{l}\text { a.m. } \\
09: 30 \\
\text { a.m. }\end{array}$ & 60 & $\mathrm{Y}$ & $\mathrm{Y}$ & $\mathrm{N}$ & 3 & $\mathrm{~N}$ & 30 \\
\hline Seattle & $\begin{array}{l}10: 00 \\
\text { a.m. }\end{array}$ & 60 & Y & $\mathrm{N}$ & $\mathrm{Y}$ & 4 & $\mathrm{~N}$ & 25 \\
\hline $\begin{array}{l}\text { Washington } \\
\text { D.C. }\end{array}$ & $\begin{array}{l}12: 00 \\
\text { p.m. }\end{array}$ & 60 & Y & $\mathrm{Y}$ & $\mathrm{Y}$ & 3 & $\mathrm{~N}$ & 14 \\
\hline Los Angeles & $\begin{array}{l}08: 15 \\
\text { a.m. }\end{array}$ & 45 & $\mathrm{~N}$ & $\mathrm{~N}$ & $\mathrm{~N}$ & 4 & $\mathrm{~N}$ & 25 \\
\hline Denver & $\begin{array}{l}12: 00 \\
\text { p.m. }\end{array}$ & 60 & Y & $\mathrm{N}$ & $\mathrm{Y}$ & 4 & $\mathrm{~N}$ & 22 \\
\hline San Diego & $\begin{array}{l}07: 30 \\
\text { a.m. }\end{array}$ & 45 & $\mathrm{~N}$ & $\mathrm{~N}$ & $\mathrm{Y}$ & 4 & $\mathrm{~N}$ & 21 \\
\hline $\begin{array}{l}\text { White River } \\
\text { Junction }\end{array}$ & $\begin{array}{l}07: 30 \\
\text { a.m. }\end{array}$ & 60 & $\mathrm{~N}$ & $\mathrm{~N}$ & $\mathrm{Y}$ & 3 & $\mathrm{~N}$ & 23 \\
\hline New Orleans & 03:00 & 60 & $\mathrm{Y}$ & $\mathrm{N}$ & $\mathrm{Y}$ & 2 & $\mathrm{~N}$ & 22 \\
\hline Milwaukee & $\begin{array}{l}\text { p.m. } \\
\text { p.m. }\end{array}$ & 60 & $\mathrm{~N}$ & $\mathrm{~N}$ & $\mathrm{~N}$ & 4 & $\mathrm{~N}$ & 5 \\
\hline
\end{tabular}

Table 2 Overall Structure and Content of Morning Report

\begin{tabular}{|c|c|}
\hline Characteristic & Values \\
\hline \multicolumn{2}{|l|}{ Format, no. $(\%)$} \\
\hline Case-based report & $193 / 225(86)$ \\
\hline Lecture-based report & $11 / 225(5)$ \\
\hline Hybrid case-based/lecture & $5 / 225(2)$ \\
\hline Other: orientation/game/EBM/combo & $16 / 225(7)$ \\
\hline \multicolumn{2}{|l|}{ Report moderator, no. $(\%)$} \\
\hline Chief resident moderator & $188 / 225(84)$ \\
\hline Attending moderator & $19 / 225(8)$ \\
\hline Resident moderator & $6 / 225(3)$ \\
\hline Combination & $12 / 225(5)$ \\
\hline \multicolumn{2}{|l|}{ Format for engagement, no. (\%) } \\
\hline Open-ended questions & $200 / 218(92)$ \\
\hline Small group discussions & $9 / 218(4)$ \\
\hline Learners called on & $2 / 218(1)$ \\
\hline Miscellaneous & $7 / 218(3)$ \\
\hline Preamble before report, no. (\%) & $144 / 225(64)$ \\
\hline Announcement & $79 / 225(35)$ \\
\hline Brief case or medical question & $62 / 225(28)$ \\
\hline Discuss resident complaints & $5 / 225(2)$ \\
\hline Discuss overnight codes & 0 \\
\hline Follow-up from prior reports & $7 / 225(3)$ \\
\hline Quality management & $12 / 225(5)$ \\
\hline Duration of preamble, median (IQR), min & $1.0(0-5.0)$ \\
\hline \multicolumn{2}{|l|}{ Learners, no. $(\%)$} \\
\hline Residents & $221 / 225(98)$ \\
\hline Interns & $215 / 225(96)$ \\
\hline Medical students & $180 / 225(80)$ \\
\hline Non-physicians & $61 / 225(27)$ \\
\hline Number of learners, median (IQR) & $15.0(11.0-19.0)$ \\
\hline Proportion of learner participation, median (IQR) & $52.4(40.0-70.0)$ \\
\hline Attendings, median no. (IQR) & $3.0(2.0-4.0)$ \\
\hline Hospitalist & $2.0(1.0-3.0)$ \\
\hline Non-hospitalist general medicine & $0(0-1.0)$ \\
\hline Specialist & $0(0-1.0)$ \\
\hline Non-internal medicine & $0(0-0.0)$ \\
\hline Program director or APD & $0(0-1.0)$ \\
\hline \multicolumn{2}{|l|}{ Miscellaneous content, no. (\%) } \\
\hline Quality and safety & $31 / 225(14)$ \\
\hline High-value care & $30 / 225(13)$ \\
\hline Social determinants of care & $20 / 225(9)$ \\
\hline Evidence-based medicine & $18 / 225(8)$ \\
\hline Ethics & $7 / 225(3)$ \\
\hline Bedside teaching & 0 \\
\hline Duration of report, median, min & $46(41.0-53.0)$ \\
\hline
\end{tabular}

$I Q R$, interquartile range; min, minutes; $A P D$, associate program director were case-based, $11(5 \%)$ were lecture-based, five (2\%) were a mix of lecture- and case-based, and 16 (7\%) were other formats including games, evidence-based medicine, and orientations. The moderator was the chief resident in $188(84 \%)$, an attending in $19(8 \%)$, a resident in six (3\%), and a combination of leaders in $12(5 \%)$. The most common method of learner engagement was open-ended questions. One hundred forty-four reports $(64 \%)$ had a preamble before the main report, including an announcement in 79 reports $(35 \%)$ or brief case or medical question such as MKSAP in $62(28 \%)$. The median number of learners present was 15 (IQR, 11.0-19.0). The most common learners were second- and third-year internal medicine residents who were present at 221 reports (98\%), interns at 215 reports $(96 \%)$, and medical students at 180 reports $(80 \%)$. Non-physician learners such as nursing or physician assistant students were present at 61 reports (27\%).

The median number of attendings present was 3.0 (IQR, 2.0-4.0). The median number of hospitalist attending was 2.0 (IQR, 1.0-3.0) compared with 0 (IQR, 0-1.0) non-hospitalist general internists, and 0 (IQR, $0-1.0$ ) specialists. Hospitalists were present more often than the other categories of attending $(p<0.001)$. Additional content areas that were incorporated into the primarily case-based reports included quality and safety $(n=31(14 \%))$, high-value care $(n=30(13 \%))$, social determinants of health $(n=20(9 \%))$, evidence-based medicine $(n=18(8 \%))$, and ethics $(n=7(3 \%))$. At no report did attendees go to the bedside or involve patient directly. The median duration of report was $46 \mathrm{~min}$ (IQR, 41.0-53.0).

The use of presentation media and digital presentation slides during morning report is described in Table 3. One hundred sixty-one $(72 \%)$ reports used digital presentation slides, 137 (61\%) used dry erase boards, 27 (12\%) used smart boards, and two (1\%) used chalk boards. Of the reports that used digital presentation slides, $114(71 \%)$ used more than 15 slides. Reports most commonly included slides with text about 
Table 3 Use of Media and Digital Presentation Slides

\begin{tabular}{ll}
\hline \hline Characteristic & No. (\%) \\
\hline Use of media, no. (\%) & \\
Use of digital presentation slides & $161 / 225(72)$ \\
Dry erase board & $137 / 225(61)$ \\
Smart board & $27 / 225(12)$ \\
Chalk board & $2 / 225(1)$ \\
Number of digital presentation slides, no. $(\%)$ & \\
$1-5$ & $18 / 161(11)$ \\
$6-10$ & $14 / 161(9)$ \\
$11-15$ & $13 / 161(8)$ \\
$>15$ & $114 / 161(71)$ \\
Content of digital presentation slides, no. $(\%)$ & \\
Text about the case & $100 / 161(62)$ \\
Labs about the case & $99 / 161(62)$ \\
Diagnostic imaging & $90 / 161(56)$ \\
Differential diagnosis & $79 / 161(49)$ \\
Professional guidelines & $48 / 161(30)$ \\
Electrocardiogram & $47 / 161(29)$ \\
Original research & $38 / 161(24)$ \\
Review articles, including UpToDate & $26 / 161(16)$ \\
Pathology about the case & $19 / 161(12)$ \\
\hline
\end{tabular}

the case $(n=100,62 \%)$, laboratory results $(n=99,62 \%)$, diagnostic imaging $(n=90,56 \%)$, differential diagnosis $(n=$ $79,49 \%)$, and professional guidelines $(n=48,30 \%)$.

A total of $198(88 \%)$ of reports either were case-based or case-based/lecture hybrids (Table 4). Most commonly, one case was discussed $(n=181(91 \%), p<0.001)$. In $109(55 \%)$ reports, the case was presented by a resident, in $74(37 \%)$ it was the chief resident, and in ten $(5 \%)$ it was an attending $(p<0.001)$. Interns and medical students only presented in one report each. In 169 of the reports (85\%), the moderator had prepared the report in advance, whereas in 29 reports $(15 \%)$, the moderator led the discussion unscripted $(p<0.001)$. The most time was spent on history (8.0 $\mathrm{min}$, IQR 4.0-11.0),

Table 4 Description of Case-Based Reports

\begin{tabular}{ll}
\hline \hline Characteristic & Values \\
\hline Number of cases discussed, no. (\%) & \\
One case & $181 / 198(91)$ \\
Two cases & $9 / 198(5)$ \\
Three or more & $8 / 198(4)$ \\
Case presenter, no. (\%) & \\
Resident & $109 / 198(55)$ \\
Chief resident & $74 / 198(37)$ \\
Attending & $10 / 198(5)$ \\
Intern & $1 / 198(1)$ \\
Medical student & $1 / 198(1)$ \\
Combinations & $3 / 198(2)$ \\
Prepared report, no. (\%) & $169 / 198(85 \%)$ \\
Unprepared, "live" report & $29 / 198(15 \%)$ \\
Case diagnosis known, no. (\%) & $173 / 198(87)$ \\
Duration, median (IQR), minutes & \\
History & $8.0(4.0-11.0)$ \\
Physical exam & $2.0(1.0-4.0)$ \\
Labs & $2.0(1.0-4.0)$ \\
Electrocardiogram & $0.0(0.0-1.0)$ \\
Imaging & $1.0(1.0-4.0)$ \\
Differential diagnosis & $8.0(4.0-11.0)$ \\
Workup & $2.5(1.0-5.0)$ \\
Management & $4.0(2.0-8.0)$ \\
Didactics & $7.0(2.0-12.25)$ \\
Other & $0.0(0.0-2.0)$ \\
\hline
\end{tabular}

$I Q R$, interquartile range
Table 5 Description of Diagnoses in 173 Reports with Known Diagnoses

\begin{tabular}{ll}
\hline \hline Characteristic & No. $(\mathbf{\%})(\mathbf{N = 2 0 0} \mathbf{a})$ \\
\hline Most common diagnoses & \\
Heart failure & $9(5)$ \\
Tuberculosis & $6(3)$ \\
Endocarditis & $6(3)$ \\
Acute coronary syndrome & $6(3)$ \\
Diabetes/diabetic ketoacidosis & $4(2)$ \\
Aspiration & $4(2)$ \\
Multiple myeloma & $4(2)$ \\
Pericardial disease & $4(2)$ \\
Vasculitis & $3(1.5)$ \\
Pancreatitis & $3(1.5)$ \\
Medication side effects & $17(9)$ \\
Most common areas of medicine & \\
Infectious diseases & $34(17)$ \\
Cardiology & $34(17)$ \\
Pulmonary critical care & $23(12)$ \\
Oncology & $18(9)$ \\
Hematology & $10(5)$ \\
Endocrine & $14(7)$ \\
Nephrology & $13(7)$ \\
Gastroenterology & $12(6)$ \\
Rheumatology & $11(6)$ \\
Neurology & $8(4)$ \\
Cases rated as rare & $83(42)$ \\
Cases rated as severe or life-threatening & $38(19)$ \\
Cases rates as either rare or severe & $100(50)$ \\
Rated rare but not severe & $62(31)$ \\
Rated severe but not rare & $17(9)$ \\
Rated as both severe and rare & $21(11)$ \\
\hline
\end{tabular}

${ }^{a}$ There were 173 reports with 200 diagnoses because some reports presented multiple patients

differential diagnosis (8.0 $\mathrm{min}, \mathrm{IQR} 4.0-11.0)$, and didactics (7.0 min, IQR 2.0-12.25).

The diagnosis was known to the moderator in 173 of the case-based reports $(87 \%)$. In total, given reports in which multiple cases were discussed, a total of 200 distinct diagnoses were presented (Table 5). A wide variety of diagnoses were presented, with the ten most common being heart failure, tuberculosis, endocarditis, acute coronary syndrome, diabetes, aspiration, multiple myeloma, pericardial disease, vasculitis, and pancreatitis. Seventeen diagnoses (9\%) were due to medication side effects (Supplement Table 1). The most commonly presented areas of medicine were infectious disease, cardiology, pulmonary critical care, and oncology. Reviewers rated 100 reports $(50 \%)$ as either rare or severe/life-threatening. In total, 83 diagnoses were rare $(42 \%)$ and 38 (19\%) were severe/life-threatening. Agreement between reviewers for rarity and severity was substantial $(k=0.73(95 \% \mathrm{CI}, 0.65-0.82)$ and $0.70(95 \%$ CI, 0.56-0.83) respectively).

Distractions were common in report (Supplement Table 2). At least one learner was paged in $57 \%$ of reports and at least one learner used their cell phone in $85 \%$ of reports. The median number of learner pages was 1.0 (IQR, 0-2.0) and the median number of learners using cell phones was 3.0 (IQR, 1.0-4.0). Attendings and chief residents were rarely paged although attendings commonly used their cell phones, which occurred in $71 \%$ reports and included a median of 1.0 (IQR, 0-2.0) attending per report. 


\section{DISCUSSION}

To the best of our knowledge, this is the first multicenter prospective descriptive study of internal medicine morning report and provides an updated look at this important educational conference. We found that morning report was predominantly case-based, moderated by a chief resident, and involved a range of learners including all levels of internal medicine resident as well as medical students and nonphysician learners. The most common attending present was a hospitalist. The most common person to present the case was a second- or third-year resident or chief resident. Interns and medical students rarely presented. The typical morning report involved a single case, which the chief resident read about prior to report and prepared a teaching presentation using digital presentation slides. A wide range of diagnoses were discussed. One-half of the diagnoses were either rare or lifethreatening. Surprisingly, the most common type of diagnosis was medication side effects. Quality and safety, high-value care, social determinants of health, and evidence-based medicine were more commonly discussed topics than medical ethics which was rarely addressed. No report that we observed went to the bedside or had a patient present.

In some respects, our findings are similar to prior descriptions of morning report. The chief resident continues to be the most common moderator. Case-based conferences predominate, with the chief resident using open-ended questions to encourage learner participation. ${ }^{11,14}$ Similar to prior studies, ${ }^{15-17}$ we found a relatively high frequency of interruptions which are associated with negative consequences on learner outcomes. ${ }^{18}$ Pager interruptions have been previously documented, ${ }^{15,19}$ although ours is the first study to document learner cell phone use during report. We also found that the most popular topic areas of internal medicine are similar to those previously described including infectious diseases, cardiology, and pulmonary critical care. ${ }^{9,11}$ Most of the specific diagnoses would be easily recognized in a morning report from decades prior, including all the specific diagnoses listed in Table 5 .

In other ways, our findings are different from prior descriptions of morning report. Traditionally, report was attended only by second- and third-year residents. At some institutions, a separate intern report was held. ${ }^{4,10,14} \mathrm{We}$ found that interns were present in $96 \%$ of reports, medical students in $80 \%$, and non-physician learners in $27 \%$. The composition of attendings has also changed. We found the most common attending present at morning report was a hospitalist (95\% of reports), while specialists and non-hospitalist general internists were present at a minority. Similarly, program directors and associate program directors were not usually present $(37 \%$ of reports), though their presence may be relatively reduced in comparison with the academic affiliate. Previously, morning report was regularly attended by the Chief of Medicine, the program director, general medicine attendings, and subspecialty attendings. ${ }^{10,12}$ Another change in morning report appears to be the preparation that the chief resident does before report. Prior studies did not explicitly quantify case preparation by the chief residents but suggest it was minimal. ${ }^{9-12}$ In our study, $85 \%$ of reports were prepared in advance and in $87 \%$ of cases the diagnosis was known to the moderator. Reflecting this change to a prepared morning report, relatively little time was spent on physical exam, laboratory results, and electrocardiograms or imaging, and more time was dedicated to differential diagnosis and didactics. Further, only $3 \%$ of reports had follow-up from the prior report, likely a result of the diagnosis being already known and thoroughly discussed. With computers and projectors now commonly available in the conference room, digital presentation slides have become the most common mode of presentation in morning report, used in more than $70 \%$, with a smart board or white board frequently used as well. Although many of the popular report diagnoses are similar to those from reports decades ago, ${ }^{9,11}$ we found that the single most common type of diagnosis was medication side effect. Lastly, we found a high rate of cases classified as rare or life-threatening in contrast to a prior study. ${ }^{12}$

We believe that the combination of extensive preparation of rare or life-threatening cases combined with the use of digital presentation slides has likely changed the educational content of morning report. On the one hand, this format allows chief residents to increase their personal knowledge of the topic and to provide greater depth while teaching. On the other hand, the use of digital presentation slides may shift the conference away from an interactive flipped classroom which is more effective than a lecture-based format. ${ }^{20-24}$ Although speculative, we also believe that the emphasis on rare and lifethreatening presentations likely has an effect on learners' diagnostic reasoning and may distort their assessment of relative probabilities when constructing differential diagnoses outside of morning report as it may lead them to biased towards these rare conditions.

Our study has several limitations. First, all sites were Veterans Health Administration hospitals which may bias the types of diagnoses given the primarily older male population. Additionally, the size, setting, and time constraints of the VA may differ from the affiliated academic center creating a different educational environment. Second, the site investigators were all hospitalists, which may have biased the type of attendings present for report. Third, although site investigators were trained using practice observations and a group discussion, interrater reliability was only assessed for the variables of "rare" diagnosis and "severe/life-threatening." Lastly, although we included ten different VA hospitals and academic programs, this is still a relatively small sample of the more than 500 internal medicine residency programs in the USA.

In conclusion, we found that morning report continues to be a predominantly case-based conference, led by a chief resident, and to cover many traditional topics of internal medicine. We found several noteworthy results including the frequent presence of medical students, non-physician learners and 
hospitalist attendings, the extensive use of digital slides to present prepared information, and the preference for rare and/or life-threatening diseases. The most time was spent discussing the history and differential diagnosis, and on prepared teaching points and didactics. Some traditional areas of internal medicine were rarely discussed, including physical exam and medical ethics. We hope our study will be useful to leaders in internal medicine resident education to inform improvements in morning report conference.

Acknowledgments: The authors would like to acknowledge the Department of Veterans Affairs.

Corresponding Author: Daniel B. Heppe, MD; VA Eastern Colorado Health Care System, Aurora, CO, USA (e-mail: Daniel. Heppe@Cuanschutz.edu).

Author Contributions All authors participated in conducting this research and contributed to the manuscript.

\section{Compliance with Ethical Standards:}

Conflict of Interest: The authors declare that they do not have a conflict of interest.

\section{REFERENCES}

1. Brotherton SE, Etzel SI. Graduate Medical Education, 2018-2019. JAMA 2019;322(10):996-1016.

2. Chaiyachati KH, Shea JA, Asch DA, et al. Assessment of Inpatient Time Allocation Among First-Year Internal Medicine Residents Using TimeMotion Observations. JAMA Intern Med 2019;179(6):760-767.

3. Gross CP, Donnelly GB, Reisman AB, Sepkowitz KA, Callahan MA. Resident expectations of morning report: a multi-institutional study. Arch Intern Med 1999;159(16): 1910-1914.

4. West CP, Kolars JC, Eggert CH, Kennedy CC, Ficalora RD. Changing morning report: evaluation of a transition to an interactive mixed-learner format in an internal medicine residency program. Teach Learn Med 2006; 18(4):330-335.

5. Parrino TA, Villanueva AG. The principles and practice of morning report. JAMA 1986;256(6):730-733.

6. McNeill M, Ali SK, Banks DE, Mansi IA. Morning report: can an established medical education tradition be validated? J Grad Med Educ 2013;5(3):374-384.
7. Hill RF, Tyson EP, Riley HD, Jr. The culture of morning report: ethnography of a clinical teaching conference. South Med J 1997;90(6):594-600.

8. Amin Z, Guajardo J, Wisniewski W, Bordage G, Tekian A, Niederman LG. Morning report: focus and methods over the past three decades. Acad Med 2000;75(10 Suppl):S1-5.

9. Ramratnam B, Kelly G, Mega A, Tilkemeier P, Schiffman FJ. Determinants of case selection at morning report. J Gen Intern Med 1997;12(5):263-266.

10. Wenger NS, Shpiner RB. An analysis of morning report: implications for internal medicine education. Ann Intern Med 1993;119(5):395-399.

11. Westman EC. Factors influencing morning report case presentations. South Med J 1999;92(8):775-777.

12. Pupa LE, Jr., Carpenter JL. Morning report. A successful format. Arch Intern Med 1985;145(5):897-899.

13. Landis JR, Koch GG. The measurement of observer agreement for categorical data. Biometrics 1977;33(1):159-174.

14. McGaghie WC, Engel JD, Wolf $\mathbf{K}$, Smith AC. Morning report: a descriptive view from two different academic settings. Res Med Educ 1985;24:157-162.

15. Blum NJ, Lieu TA. Interrupted care. The effects of paging on pediatric resident activities. Am J Dis Child 1992;146(7):806-808.

16. Katz MH, Schroeder SA. The sounds of the hospital. Paging patterns in three teaching hospitals. N Engl J Med 1988;319(24):1585-1589.

17. Mendel A, Lott A, Lo L, Wu R. A Matter of Urgency: Reducing Clinical Text Message Interruptions During Educational Sessions. J Hosp Med 2018;13(9):616-622.

18. Zureick AH, Burk-Rafel J, Purkiss JA, Hortsch M. The interrupted learner: How distractions during live and video lectures influence learning outcomes. Anat Sci Educ 2018;11(4):366-376.

19. Wieland ML, Loertscher LL, Nelson DR, Szostek JH, Ficalora RD. A strategy to reduce interruptions at hospital morning report. J Grad Med Educ 2010;2(1):83-84.

20. Myers CG, Sateia HF, Desai Sv. Association Between Team Learning Behavior and Reduced Burnout Among Medicine Residents. J Gen Intern Med 2018;33(12):2037-2039.

21. Hew KF, Lo CK. Flipped classroom improves student learning in health professions education: a meta-analysis. BMC Med Educ 2018;18(1):38.

22. Schynoll G, Irish E, Wayne J, Smith R. Feasibility of a Comprehensive Medical Knowledge Curriculum in Internal Medicine Using Team-Based Learning. J Grad Med Educ 2018;10(1):78-83.

23. Hebert RS, Wright SM. Re-examining the value of medical grand rounds. Acad Med 2003;78(12):1248-1252.

24. Deslauriers L, McCarty LS, Miller K, Callaghan K, Kestin G. Measuring actual learning versus feeling of learning in response to being actively engaged in the classroom. Proc Natl Acad Sci U S A 2019;116(39):1925119257.

Publisher's Note: Springer Nature remains neutral with regard to jurisdictional claims in published maps and institutional affiliations. 